\title{
Bone mineralization and hormonal status in Turner syndrome patients: cross sectional one population study
}

R. Klimaite ${ }^{1,2}$, R. Krikščiuniene $e^{1,2}$, B. Žilaitiene ${ }^{1,2,3}$, R. Verkauskiene 1,2,3 $^{\text {. }}$

${ }^{1}$ Hospital of Lithuanian University of Health Sciences, Kauno klinikos.

2 Lithuanian University of Health Sciences

3 Institute of Endocrinology, Lithuanian University of Health Sciences

\section{Introduction}

Women with Turner syndrome (TS) are known to be at risk of decreased bone mineral density (dBMD). Sex hormone replacement therapy is crucial to ensure the proper BMD formation, although the dBMD remains a problem in TS.

\section{Aim}

To investigate the prevalence of decreased bone mineralization and it's association with hormone levels in TS.

\section{Subjects}

Women with geneticaly confirmed TS aged $\geq 18$ year.

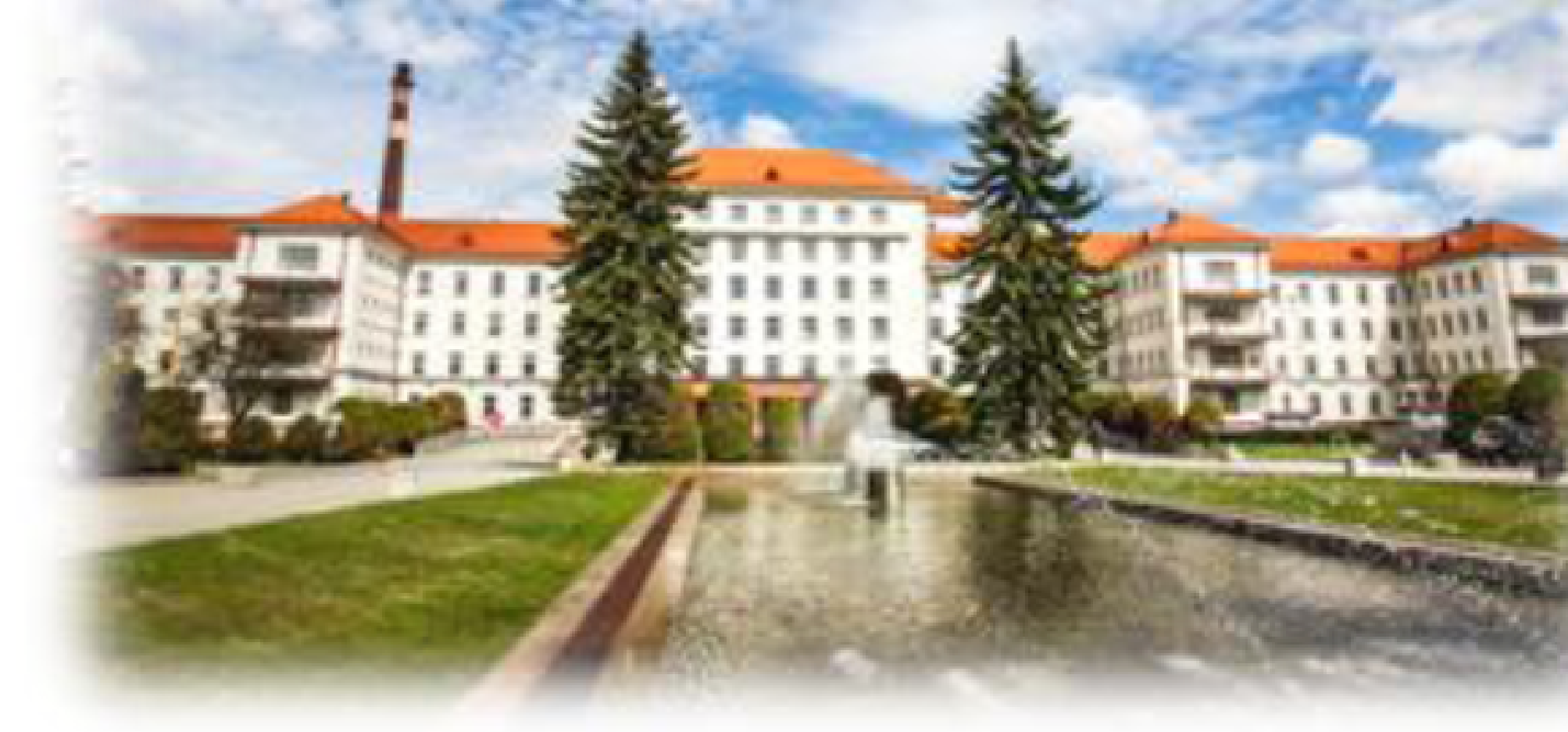

\section{Methods}

There were 53 women with TS enrolled into the prospective study. To assess the BMD dual energy - $X$ - ray absorptiometry (DEXA) parameters were analysed. BMD was meassured in $\mathrm{g} / \mathrm{cm}^{2}, \mathrm{Z}$ - score $\leq-2.0 \mathrm{SD}$ was defined as dBMD (International Society for Clinical Densitometry guidelines ${ }^{1}$ ). The lowest value of Zscore in the spine or in the neck of femur was included into the analysis. The correlations between BMD and the levels of Testosterone (T), Estradiol (E), Thyroid stimulating hormone (TSH), calcium $(\mathrm{Ca})$, ionized calcium $\left(\mathrm{Ca}^{2}+\right)$, body mass index (BMI), final height $(\mathrm{FH})$, the duration of $\mathrm{E}$ use (DE), were evaluated.

\section{Results}

Mean age of participants was $29.06 \pm 7.19$ year. Mean $\mathrm{FH}$ was $152.33 \pm 6.21 \mathrm{~cm}$, mean weight $57.19 \pm 11.40 \mathrm{~kg}$, mean BMl $24.59 \pm 4.82 \mathrm{~kg} / \mathrm{m}^{2}$, mean BMD was $0.787 \pm 0.144 \mathrm{~g} / \mathrm{cm}^{2}$. dBMD was diagnosed in $26.5 \%(n=13)$ of TS, normal BMD was found in $73.5 \%(n=36)$. Figure 1

The significant correlation between BMD and BMI was observed $(r=0.309, p=0.039)$. Figure 2

The significant negative correlation between $\mathrm{DE}$ and $\mathrm{Ca}$ $(r=-0.317, p=<0.05)$ was found .Figure 3

There was no significant correlation between BMD and T, E, TSH and $\mathrm{Ca}$ or $\mathrm{Ca}^{2}+$ levels.

\section{- dBMD normal BMD}

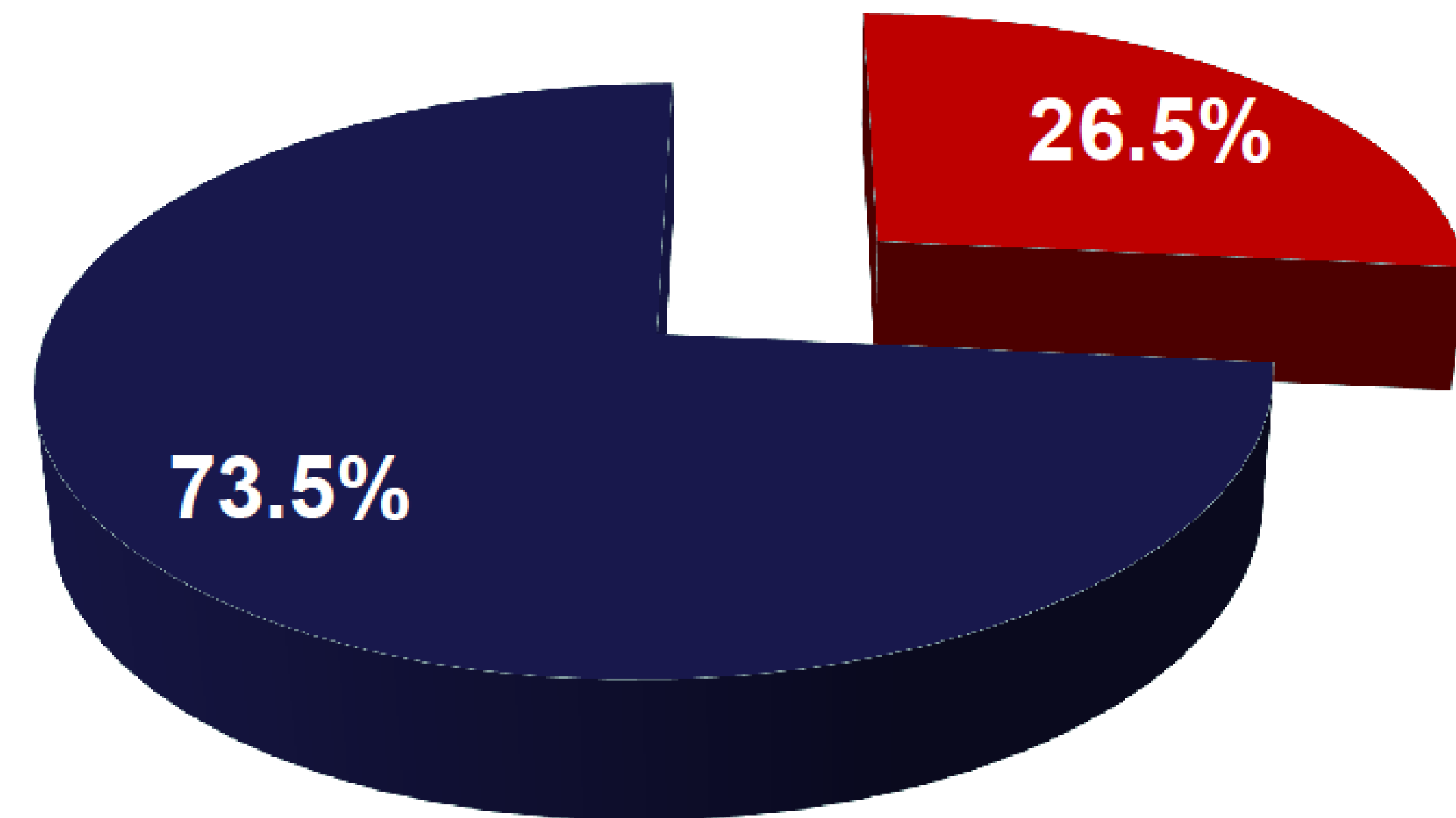

Figure 1. Distribution of women with TS according to BMD

\section{Conclusion}

Higher BMI was associated with better BMD in TS patients. No relationship between sex hormone, TSH, calcium concentrations and BMD was identified in this study.

\section{References}

'Lewiecki E. M., Binkley N., Morgan S. et al. Best Practices for Dual-Energy X-ray Absorptiometry Measurement and Reporting: International Society for Clinical Densitometry Guidance . Journal of Clinical Densitometry 2016; 19; 127-140.

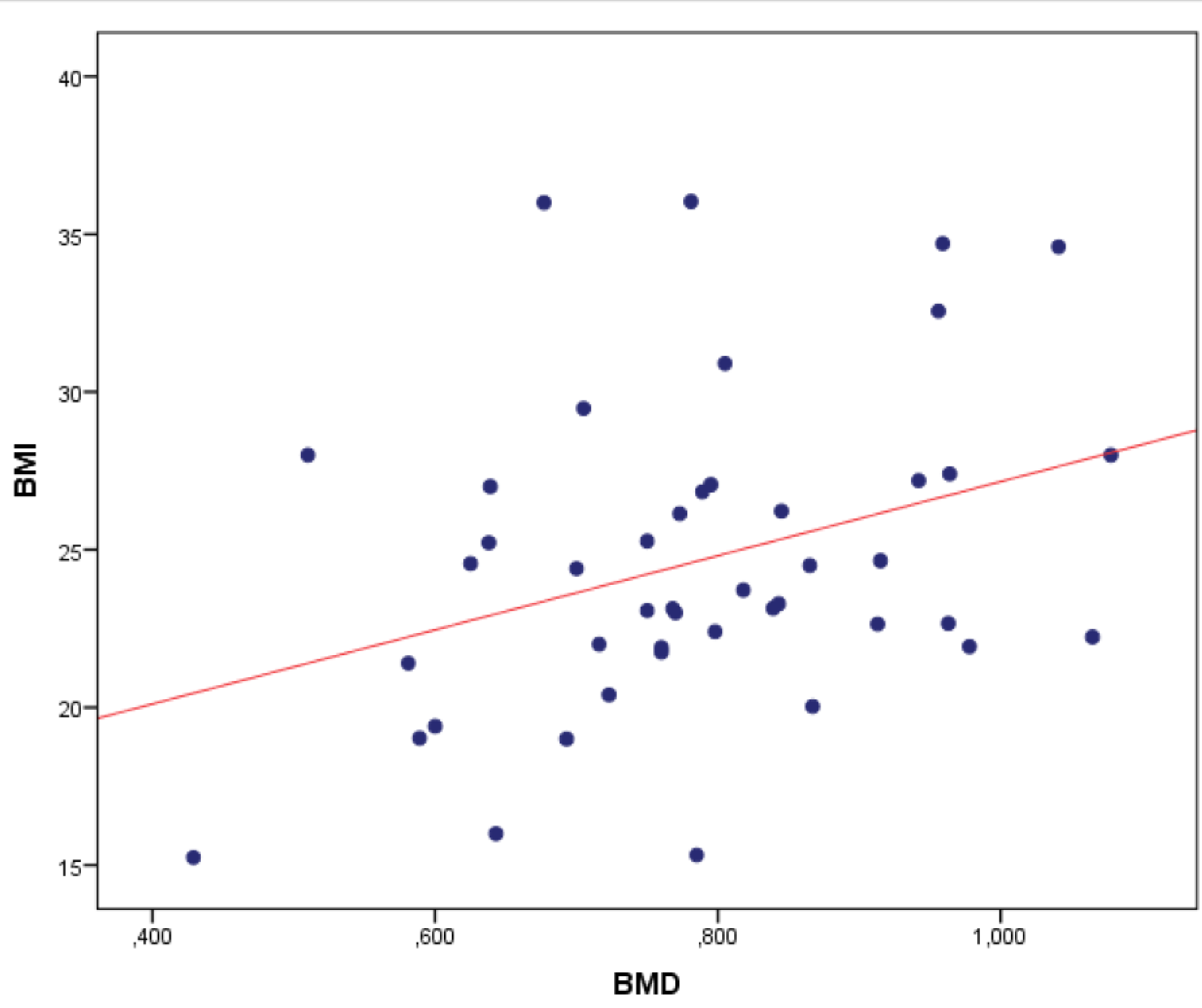

Figure 2. The relation between BMI and BMD.

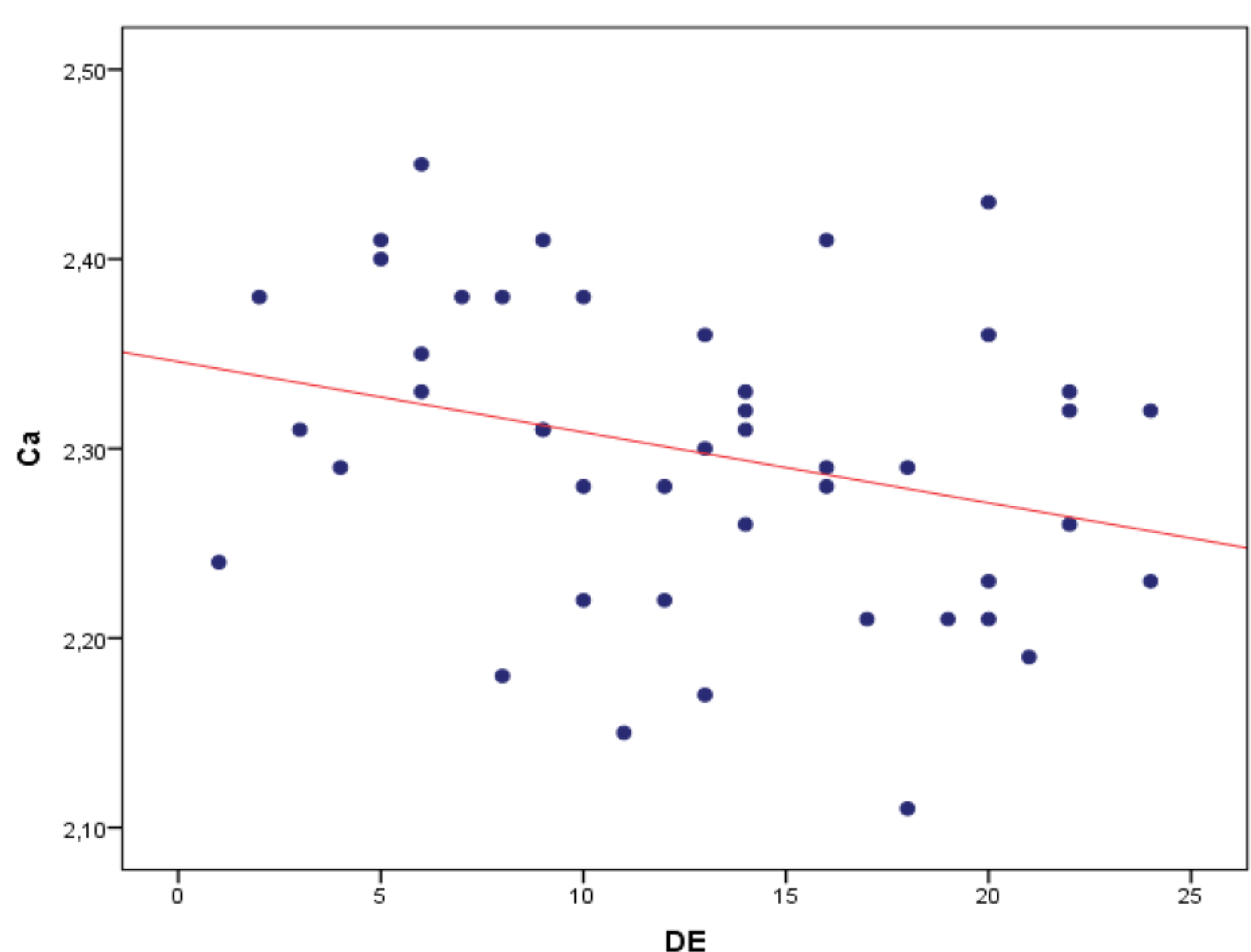

Figure 3. The relation between $\mathrm{DE}$ and $\mathrm{Ca}$. 